EDITORIL

\title{
Investment in research and development
}

Global competition and development of knowledge based economies are major challenges faced by all nations. In response, both the developed and developing nations have adopted various strategies to face these challenges. Great efforts are made to increase and improve the necessary resources in science and technology (S\&T) and the number of S\&T personnel which will in turn accelerate research and development. This acceleration of research will result in innovations leading to the development of key S\&T based industries and improve the national economy.

Human resource development is a key area of concern when one considers the development of research in S\&T. It is necessary to develop quality researchers and this is a responsibility of the universities. The demand for high quality researchers is bound to increase and universities will have to develop plans to progressively increase the training of skilled S\&T personnel at all levels. It is important to bear in mind the significant role the supporting staff plays in a successful research team. The training of technical personnel is as important as training of scientists.

A research and development workforce is of prime importance to S\&T development. All efforts must be therefore made to sharply increase the research development density which is the number of researchers per 1000 employed persons. Both the government and the private sector have the responsibility in achieving this increase. It is also necessary to create a more competitive academic environment within the universities and also establish research centres of excellence both within and outside the universities which would result in quality patents and innovations.

To accelerate and develop research of academic excellence in new fields, the country must also attract internationally accepted world class researchers and develop teams capable of making outstanding contributions and innovations in S\&T. This level of academic research and knowledge creation will result in innovations leading to industrial development. A vibrant community of S\&T researchers can be developed through an interchange of personnel from academia, research sector and industry at the local as well as international levels. It is encouraging to note that initiatives have already been taken to fund such programmes for partnerships between academia and industry.

Since R\&D is the driving force of industrial innovations which accelerates economic development, it is necessary for the government to actively invest in R\&D. It is expected that the government will steadily increase the annual allocations for this. It then becomes the responsibility of the researchers to show significant results to match the investments. The government cannot alone meet the demands of the necessary investments. It is also necessary for the private sector to play a major role in this effort. The private sector can contribute significantly in this national venture by devoting greater inputs into $R \& D$. The joint effort of the government and the private sector must be directed towards a gross domestic expenditure on R\&D towards a target in excess of $1 \%$ of the GDP in the immediate future.

Scientists and technologists have an enormous responsibility to make maximum use of their knowledge and expertise as well as the investments in S\&T to contribute to the economic development of the country. Making the difference to lead the country towards sustainable economic and social development that would achieve the goals of poverty alleviation and provision of quality life style for our people should be the vision of all scientists and technologists.

Nalini Ratnasiri 